\title{
Multi-Sensor System for Land and Forest Fire Detection Application in Peatland Area
}

\author{
Evizal Abdul Kadir ${ }^{1}$, Sharul Kamal Abdul Rahim², Sri Listia Rosa ${ }^{3}$ \\ ${ }^{1,3}$ Department of Informatics Engineering, Universitas Islam Riau, Riau, Indonesia 28284 \\ ${ }^{2}$ Wireless Communication Center, Universiti Teknologi Malaysia, Johor Bahru, Malaysia 81310
}

\begin{tabular}{l}
\hline Article Info \\
\hline Article histories: \\
Received Sep 9, 2019 \\
Revised Nov 28, 2019 \\
Accepted Dec 20, 2019 \\
\hline
\end{tabular}

\section{Keywords:}

Multi-sensor

Forest fire

Peatland

WSNs

\begin{abstract}
Forest fire has a dangerous impact on environments and humans because of haze and carbon emitted from it. A common technology to detect fire hotspots is to use satellite images and then process them to determine the number of hotspots and their location. However, satellite systems cannot penetrate in bad weather or cloudy condition. This research proposes a ground sensor system, which uses several sensors related to the indicators of fire, especially fire in peatland area with unique characteristics. Common parameters of fire, such as temperature, smoke, haze, and carbon dioxide, are applied in this system. Indicators are measured using special sensors. Results of every sensor are analyzed by implementing intelligent computer programming, and an algorithm to determine fire hotspots and locations is applied. The fire hotspot location and intensity determined by integrated multiple sensors are more accurate than those determined by a single sensor. Data collected from every sensor are kept in a database, and a graph is generated for reporting and recording. In case of sensor readings with parameters, potential of fire and hotspots detected can be forwarded to the representative department for corresponding actions.
\end{abstract}

Copyright $(0) 2019$ Institute of Advanced Engineering and Science. All rights reserved.

\section{Corresponding Author:}

Evizal Abdul Kadir,

Department of Informatics Engineering, Faculty of Engineering

Universitas Islam Riau,

Jl. Kaharuddin Nasution No.113, Marpoyan, Pekanbaru, Riau, Indonesia 28284

Email: evizal@eng.uir.ac.id

\section{INTRODUCTION}

Forest fires in Indonesia are considered a regional and global issue; the fire impact spreads to the neighboring countries, and gases emitted into the atmosphere (e.g., carbon dioxide) can cause global warming. Initial forest fires are thought to occur naturally because of dryland and warm environment; however, fires in the last decade have been started due to human activities, such as hunting and opening up patches of agriculture in the forest. Although fires have been a feature of forests in Indonesia for hundreds of years, initial fires may have been smaller and more dispersed in terms of frequency and time than in the past two decades. These initial fires are not the cause of significant deforestation. All distribution of peat deposits is in the quaternary alluvium sedimentary group in the quaternary period. The location is relatively near the beach to tens of kilometers inland. The maximum thickness reached is 15 meter in the Riau area. Peat deposits can be determined and differentiated "megascopically" in the field because they are above the Earth's surface. Megascopic peat deposits are generally characterized by very soft physical properties resembling "soil," "mud," or humus from a combination of decaying plants, such as leaves, stems, twigs, and roots of various species. The level of decay of plants is generally determined and influenced mainly by the depositional environment (anaerobic or aerobic) and the composition of the organic material (the content of lignin, cellulose, cinn, and humic acid).

Peat deposits are generally light brown to dark brown to blackish dark, very soft, easily pricked, and leave a dark liquid and remnants of plant waste when squeezed by hands. They are obtained from the surface of the earth up to several meters thick. Surface peat deposits can be overgrown with various types and species 
of plants ranging from moss to bush and large trees. Darker peat usually shows a strong decay rate. Megascopic tropical peat generally consists of remnants of roots, stems, leaves, and fibers in abundant quantities. On the contrary, moss peat is dominated by remnants of moss plants, as found in Finland (Northern Europe). Figure 1 shows the area in Indonesia with a high spread of peatland.

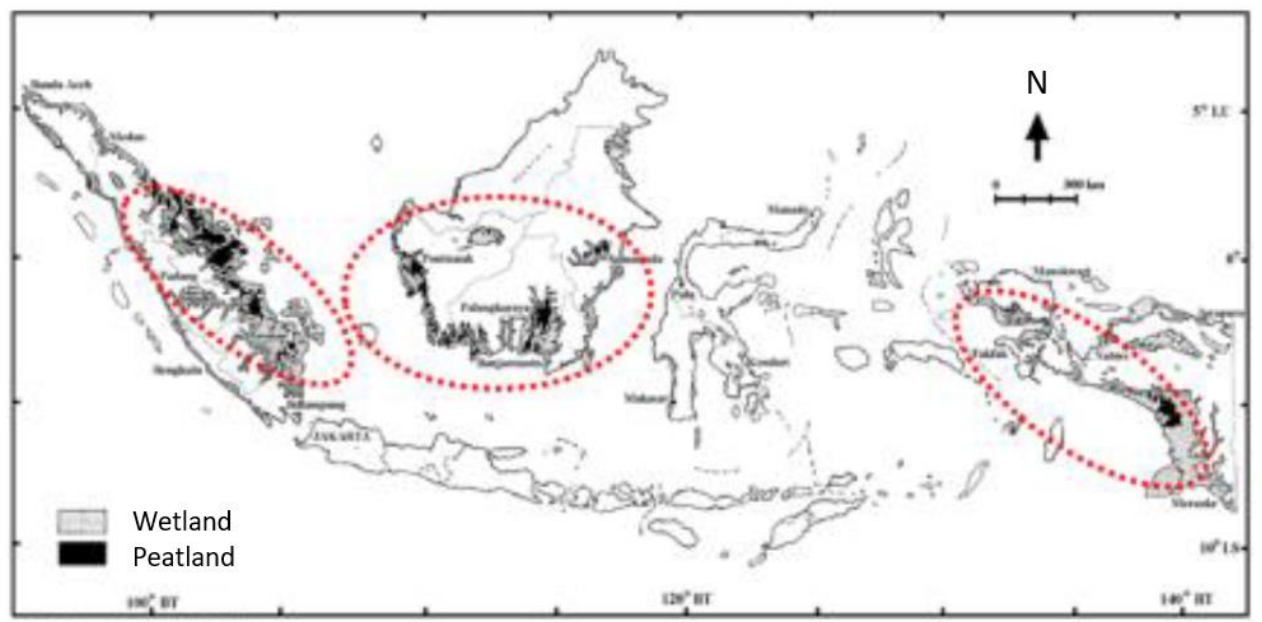

Figure 1. Peatland map area in Indonesia

The impact of fires that are felt by humans in the form of economic losses is a benefit from forest potentials, such as forest trees that are commonly used by humans to meet their needs for building materials, food ingredients and medicines, and animals to meet the needs for animal protein and recreation. Other disadvantages include ecological losses, such as the reduction of forest area, the unavailability of clean air produced by forest vegetation, and the loss of the function of the forest as a water regulator and preventing erosion. The direct impact of forest fires is listed as follows. First, acute respiratory infections arise in the community. Second, the community is disadvantaged socially and economically because of the reduced efficiency of work, offices, and schools and disrupted transportation. Third, immaterial and material losses to the local community cause transboundary haze pollution (cross-boundary smoke pollution) to the region of neighboring countries, such as Singapore, Malaysia, and Brunei Darussalam. This research proposes a method to prevent forest fire by designing a new sensing system to detect and estimate the potential of fire in Riau Province, Indonesia. Contrary to other studies, this research focuses on peatland, which is a special type of land and is challenging for newly designed sensors and systems.

\section{RELATED WORKS}

This research of forest fire detection uses multiple sensors to achieve accurate information on the potential of forest fire occurrence. Previous works [1-3] used probabilistic neural network data fusion algorithm to detect the potential of fire based on texture features from the fire scene. Some of the information on the environmental temperature and smoke concentration was collected for processing. In [4, 5], a web-based communication module of multiple sensors was designed and implemented to detect fire. The system has a notification system. Global system for mobile communication (GSM) technology has also been used. The GSM module sends data of fire alerts to the representative officer and generates notifications based on the web in real time. Web-based notification systems are designed for remote notification and fire alert.

In $[6,7]$, a processing method different from the traditional signal was proposed. The multi-sensor system information fusion can be merged at different levels. In [8], forest fire was detected using an atmosphere system to check radiative fire. However, this system only conducts simulation. The Wi-Fi system was used in [9-11] to detect fire. However, the indoor application requires a fuzzy logic system. Wireless sensor network (WSN) system has been used to easily reconfigure the topology in the communication of data. The system applies several sensors, such as temperature, gas concentration, and visibility sensors. An adaptive method based on multilayer perceptron for the processing of measurement results in a multi-sensor system was proposed in $[12,13]$. Multi-sensor systems for the detection of fire apply various algorithms to increase sensitivity and implement devices to reduce nuisance alarms $[14,15]$.

Wireless multi-sensor systems are implemented for fire detection in WSN node and algorithm to determine the probability of fire. The fire detection system comprises the low-power electrochemical carbon monoxide sensor, photoelectric smoke detector, and semiconductor temperature sensor. In [16, 17], algorithm 
for the program in an embedded system was used to detect fire in the standard room of the State Key Laboratory of Fire Science of China. In [18], forest fire was detected using a prediction model based on two-stage adaptive duty. However, some of the detected hotspots are inaccurate. The Internet of Things (IoT) technology has also been used in the detection of forest fire $[19,20]$. IoT systems provide alerts and broadcasts information and are currently widely used.

\section{MULTI-SENSOR SYSTEM FOR PEATLAND FIRE DETECTION}

Current technologies to detect forest fire mostly use satellite images and analyze them to determine fire hotspots. Multi-sensor systems for fire detection have been introduced by some researchers, but only a few parameters of forest fire have been used. This research proposes a multi-sensor system for forest fire detection, especially in peatland area with unique and different parameters of fire. The design of sensor consists of several sensors related to the soil parameters of peatland. The impact of fire from the soil is analyzed to determine the optimal type of sensors and methods to analyze the data from the peatland fire. Four types of sensors are used to detect temperature and humidity, which are basic environmental parameters, and carbon and haze, which are related to peatland.

\subsection{Peatland}

Peatland was formed at the beginning of Quaternary in ice age (diluvium). This formation results in a decrease in sea level (regression). This phenomenon causes strong erosion upstream of the river and produces coarse rock deposits, such as gravel and gravel, which are collectively called "old alluvium" deposited in over tertiary sediments that form the basis of the peat basin. At the end of the regression phase in the "warm" period (i.e., at the end of the "Pleistocene" to the beginning of Holocene) with the melting of the ice, the increase in seawater is accompanied by an increase in temperature and rainfall in the regions of Sumatra and Kalimantan. This situation forms rocks along "Bukit Barisan," Swaner, and Meratus. Strong chemical weathering occurs and fine clay deposits are produced on the coastline in the East Coast of Sumatra and south Kalimantan. Accordingly, the coastline progresses toward the sea. Ultimately, river embankments, meanders, and swamps are formed and are soon overgrown by swampy plants, such as "Nipah" and mangroves. Figure 2 illustrates the peatland formation.

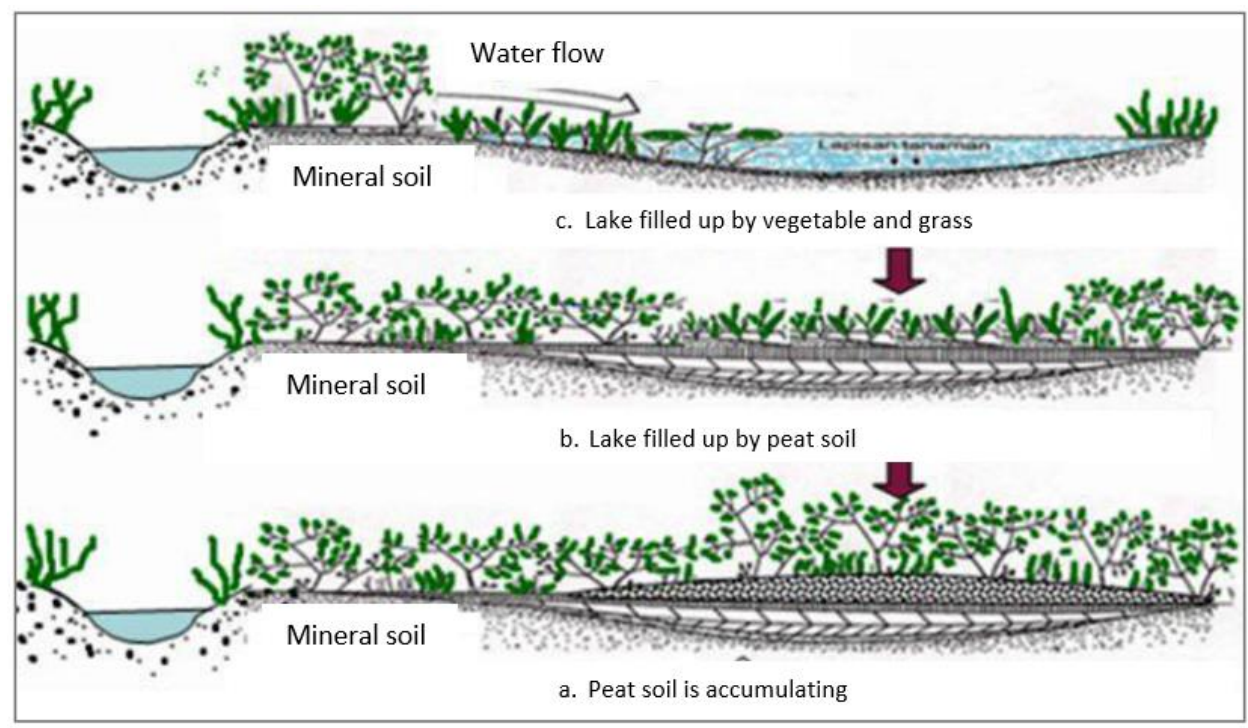

Figure 2. Example of peatland formation

The characteristics of peatland are due to that the initial process of its formation is largely determined by the following elements and factors:

- Types of plants (evolution of flora growth), such as mosses, grass, and wood.

- Humification process (temperature or climate); and

- Its depositional environment (paleogeography).

\subsection{Wireless Sensor Network (WSN)}

The WSN hub sensor node collects data from each sensor node and forwards the data to the base station or co-ordination center. The data package that is received and forwarded by the hub node contains the address and measurement values (temperature, humidity, smoke, and carbon) of the original sensor node. The 
WSN hub node has uninterrupted power supply, and the communication channel between the hub node and co-ordination center is unremitting. Thus, the hub sensor is assumed as "constantly available" in the simulation. Figure 3 shows a design of communication to the backend system. Every sensor node, which represents a forest fire sensing system, has its own sink node for collecting data and keeping the local host before sending to the backend system. The proposed multi-sensor system for forest fire applies $4 \mathrm{G}$ network for communicating from sink node to backend, which is the database or data center for fast transfer of data and real-time monitoring.

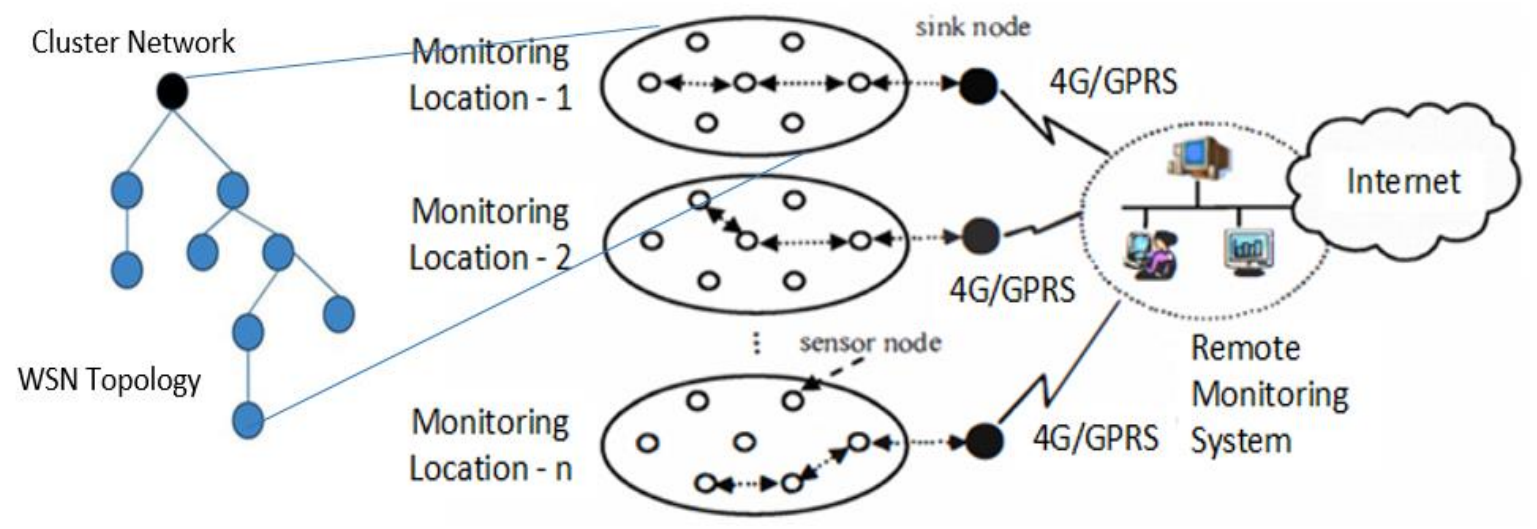

Figure 3. Architecture of WSNs proposed in this system

\subsection{Proposed Multi-Sensor System}

WSN technology can be applied in various fields, such as remote environmental monitoring, industrial automatic control, remote sensing, and target tracking. In this case, the technology is used to environmental monitoring for detecting land and forest fire in real time. Ideally, a WSN system consists of a few number of sensor nodes in a system that connect one another with the communication system. The proposed multi-sensor system is required because of the various parameters in a forest fire. Accordingly, all the parameters should be measured and monitored. The monitored parameters are temperature, humidity, carbon dioxide, smoke, and haze. Figure 4 shows a block diagram of the proposed designed system for land and forest fire sensing with multi-sensor. The data detected from all the sensors in the internal memory system of the sensor node are forwarded to the WSN gateway system due to its large capacity of data memory. In the gateway system, unused data are filtered to minimize the large number of data to be sent to the backend system.

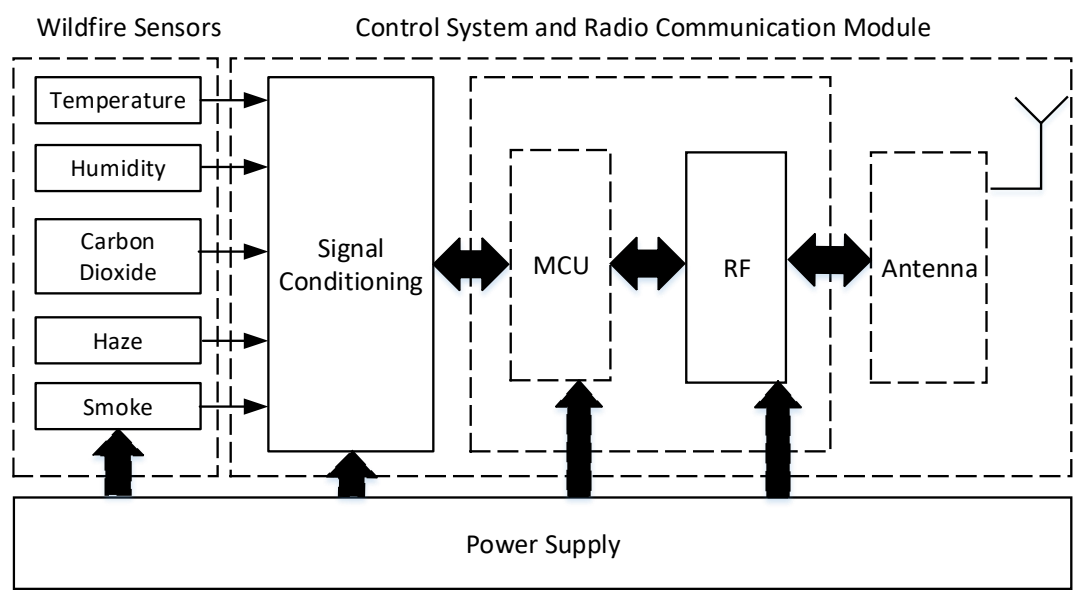

Figure 4. Block diagram of forest fire sensor using multi-sensor

The information detected from the sensors is kept in an internal memory before sending to the monitoring system (backend system). The location monitoring system (sensing node) is very far from the backend system with a distance of up to $200 \mathrm{~km}$. Thus, no facility of power supply is available. Accordingly, a solar panel system is applied to the sensing node to generate power. The latest technology of communication system, namely, 4G technology, is applied in this communication system, from its sensing nodes to its backend system. Figure 5 shows the block diagram of data communication to the backend system for monitoring. 


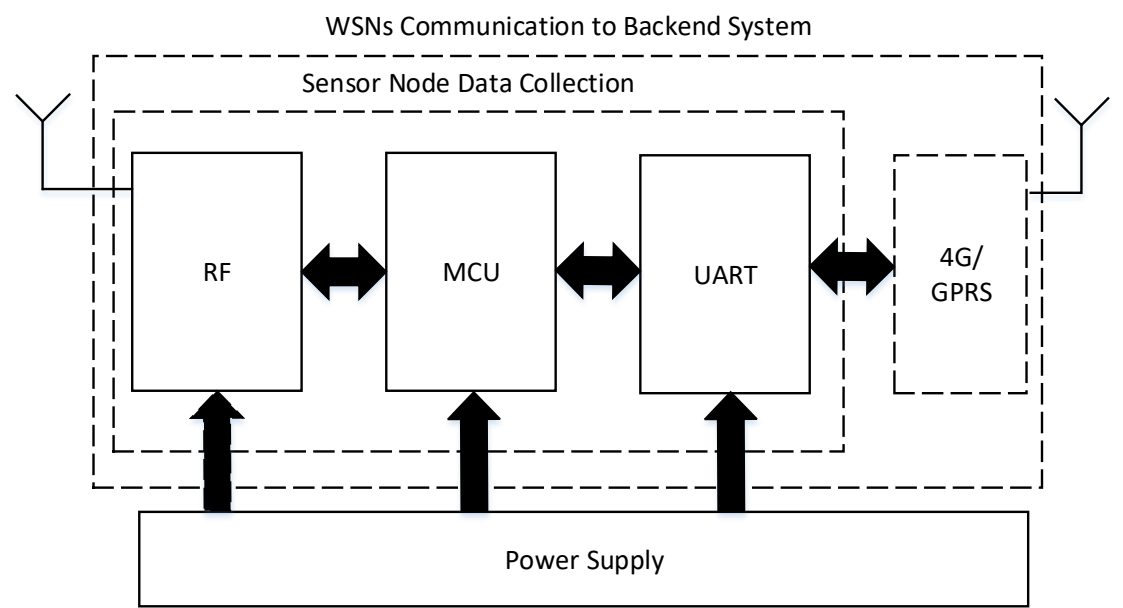

Figure 5. Block diagram of communication to backend system

The proposed design of sensing node for forest fire detection using WSN system in peatland area is a new method for ground sensing technology. The data of forest fire parameters collected from multiple sensors are used to detect abnormal condition. A multi-sensor system is designed on the basis of the sample data analysis to detect forest fire and material or chemical emitted from the forest fire.

\subsection{Forest Fire Modeling in Peatland Area}

Forest fire hotspot is different in each of area: some areas have very high and many fire hotspots, whereas others have low number. To estimate the total hotspots with common geography by assuming a set of multiple WSN sensors deployed in a region of the area to be monitored, the function of coverage $\mathrm{P}$ is given as (1).

$$
\begin{aligned}
& P=f(x, y, t)=\left\{\left(\mathrm{x}_{1}, \mathrm{y}_{1}\right) \ldots\left(\mathrm{x}_{\mathrm{n}}, \mathrm{y}_{\mathrm{n}}\right)\right\}, \\
& \left(\mathrm{x}_{\mathrm{k}}, \mathrm{y}_{\mathrm{k}}\right)=f(t), k=1,2,3, \ldots n
\end{aligned}
$$

$(\mathrm{x}, \mathrm{y})$ represents the coordinate of the sensing system that is installed on the ground of forest with large coverage area to be monitored. In this case, the WSN system is static. In other words, the sensing node is fixed in the location. The sensing node is expected to collect a large amount of data in actual condition and stop operating in certain times. The case defined by the coverage of the index area is IP, which is a scalar value representing the amount of percentage coverage area to be monitored within a specific time. IP can be calculated as (2).

$$
\mathrm{IP}=\frac{\text { area covered with sensors }}{\text { the total area of the surveillance region }} \cdot 100 \%
$$

The model of WSN system based on basic components in a multiple sensor node can be defined as a vector in (3).

$$
S=(d, E(t))
$$

where $d$ is the distance of sensing power transmitting in radius of range area and the distance of covered area by a number of sensing nodes for exchange and communication of neighboring nodes. $E(t)$ is the availability of energy in sensing node. The parameter of network can be described as a vector in (4).

$$
M=\left(n, \mathrm{f}_{0}, \Delta E\right)
$$

where $\mathrm{n}$ is the number of sensors in the area of forest, fo is the transmission of the frequency in regular interval, and $\Delta \mathrm{E}$ is the consumption of the energy per transmission. $\Delta \mathrm{E}$ also comprises energy spent in a sensor node and processing of data. Each node has two roles:

(a) Sensing of environmental data and its transmission.

(b) Receiving data from every neighboring node and forwarding them to the gateway station. 
The number of objects in sensing node surveillance is modeled as a four-side stationary polygon and defined as a set in (5).

$$
O=(A, B, C, D)=\left\{\left(\mathrm{x}_{\mathrm{A}}, \mathrm{y}_{\mathrm{A}}\right),\left(\mathrm{x}_{\mathrm{B}}, \mathrm{y}_{\mathrm{B}}\right),\left(\mathrm{x}_{\mathrm{C}}, \mathrm{y}_{C}\right),\left(\mathrm{x}_{\mathrm{D}}, \mathrm{y}_{D}\right)\right\},
$$

where A, B, C, and D are the sensing points of polygon with coordinates of $(\mathrm{x}, \mathrm{y})$.

\subsection{Forest Fire Detection Decision}

The decision of forest fires alert raising up once sensors detected abnormality value from the sensors, multi-sensor push the data to the controller system and analyzed use algorithm to compare the parametrs. Once threshold limit met-up then system detected fire happen and forward alert to the system and authority. Figure 6 shows a flow process of decision to conclude a fire was happening according to the sensors detected the fire parameters. An algorithm introduced in the system to make decision more precise and accurate based on multi parameters received, a forest fire happen because of longer time and multi parameters geeting abnormal. If the abnormaliy detected only for a sensor, then system checked others possibility that the values raise-up because of sensors introduced of noise. In the case of forest fire detected then system sending an alert to the respective authority for further action and store all the data to the server as record for the abnormality detetcted. Similar to the action taken, every data sensed by sensors store the data in the database for the records.

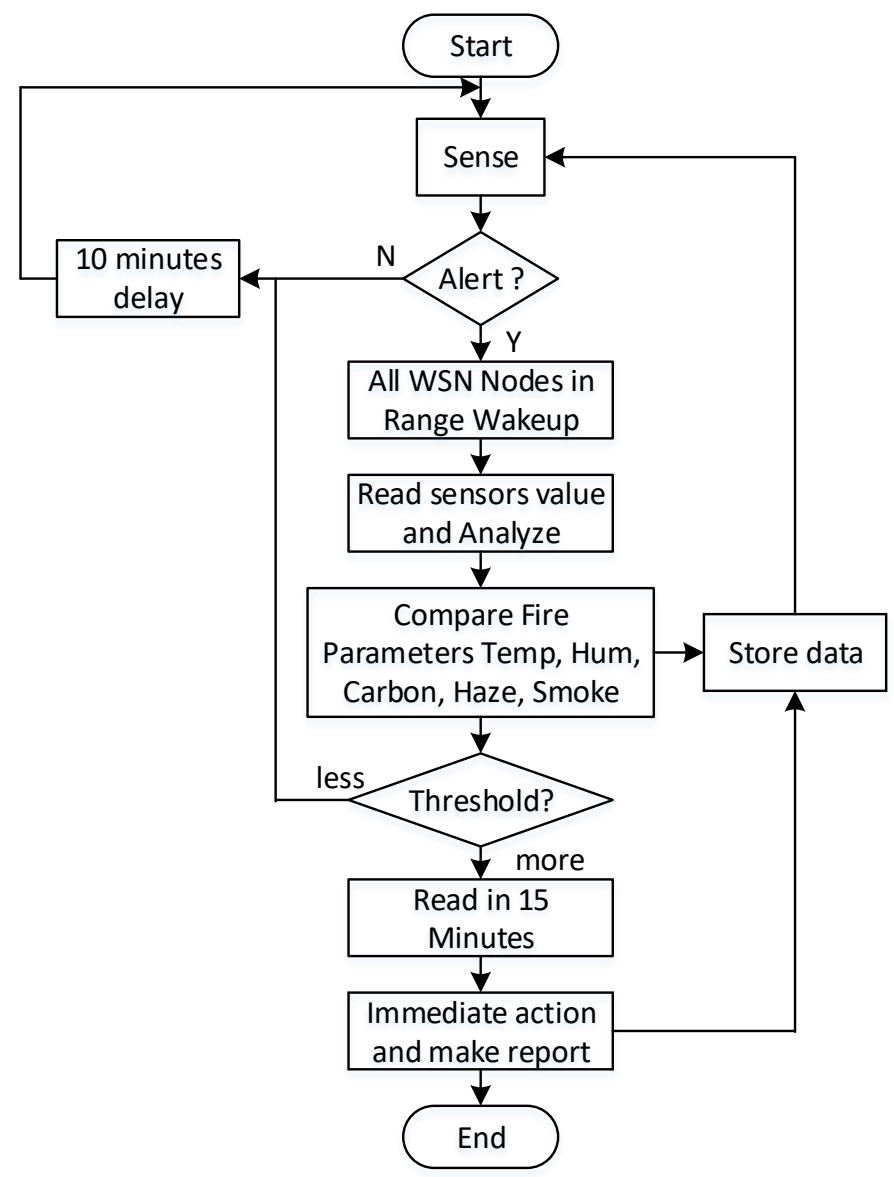

Figure 6. Flow of decision making for fire alert

\section{RESULTS AND DISCUSSION}

The proposed new design of forest fire detection for peatland area is tested. The sensors can detect all parameters that indicate potential fire in the peatland forest area. The sensor system is designed with four sensors, namely, temperature, humidity, smoke, and carbon sensors. Figure 7 shows the assembled multiple sensors for the detection of fire hotspots. These sensors are related to fire parameters. 


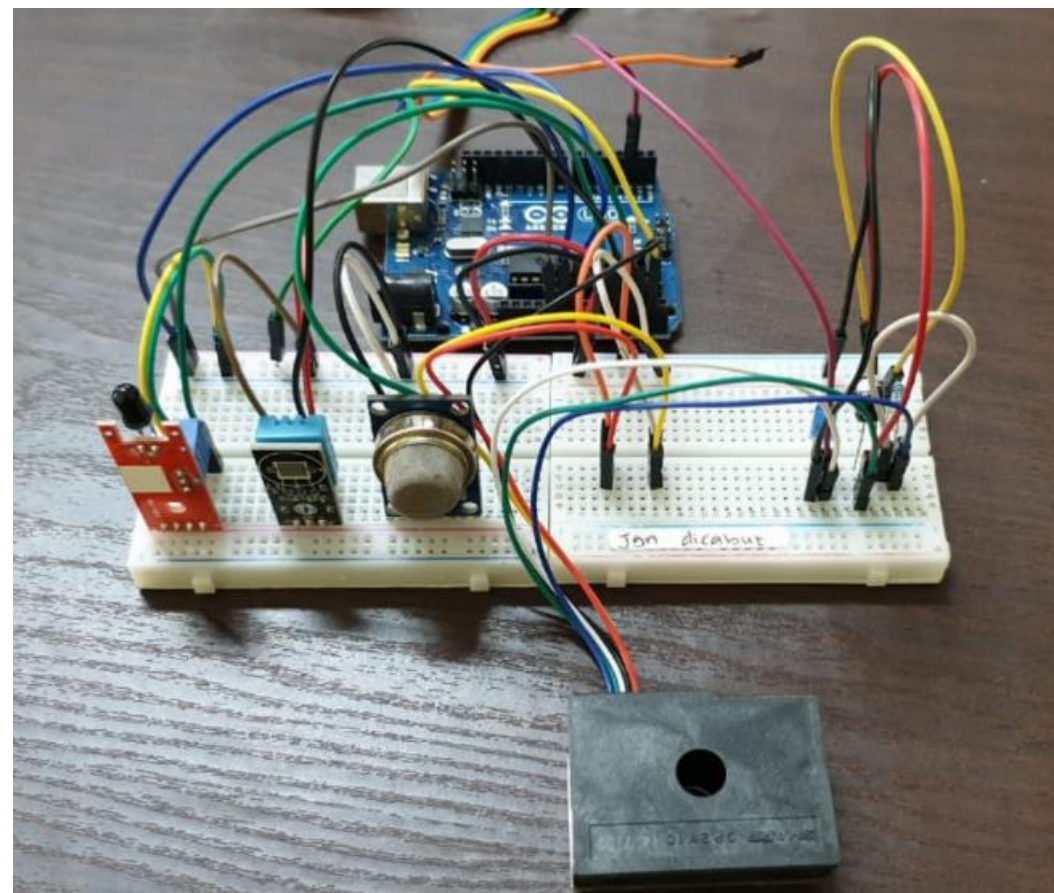

Figure 7. Assembled sensor node for fire detection

The detection data from the sensors are kept in the Arduino memory, and some filtering is conducted to this module to avoid waste of data. All the data collected from the sensor are analyzed using an intelligent programming system to determine whether the data received indicate potential fire. This programming can differentiate normal fire and forest or land fire that becomes a wildfire. Among the many parameters that indicate potential of fire, environment temperature is the most important. Figure 8 shows the testing of environment temperature using the temperature sensor. All readings are kept in the internal data logger.

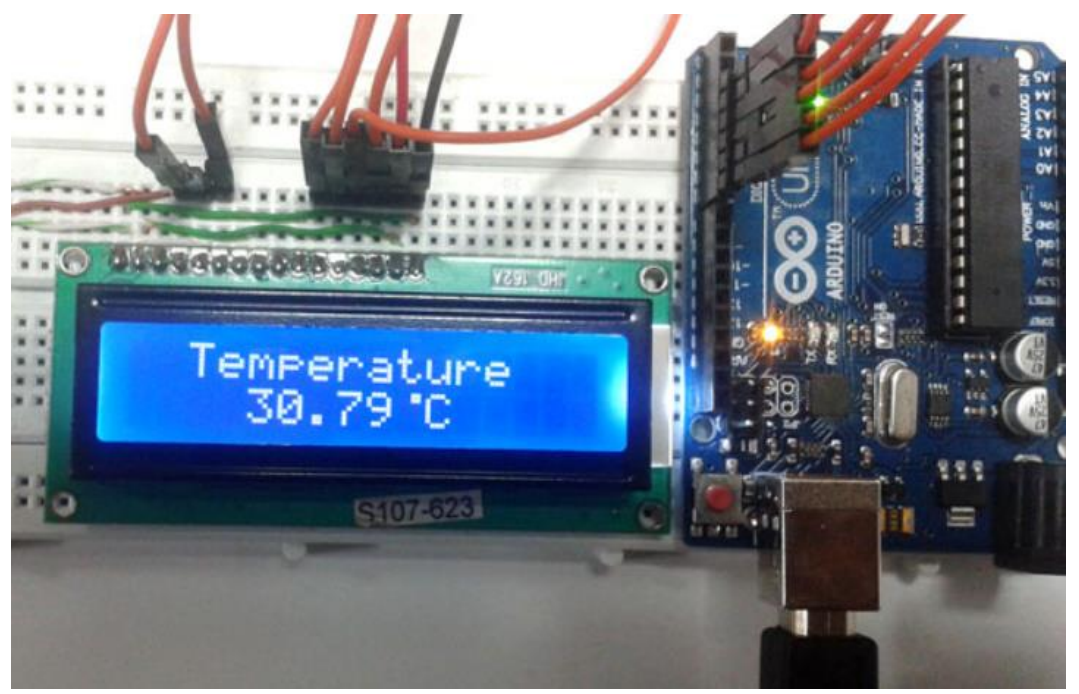

Figure 8. Results of temperature measurement

Apart from environment temperature, humidity indicates the potential of fire. Humidity is measured using its related sensor that is integrated to the temperature sensor in the Arduino processing module. Figure 9 shows the assembly and testing of humidity in the laboratory environment. The readings of temperature and humidity are shown in an LCD display. Then, all the data are kept in a data logger inside the module for recording. In a certain period, all the data collected by the Arduino module with filtered data are sent to the monitoring system for analysis and permanent recording. 


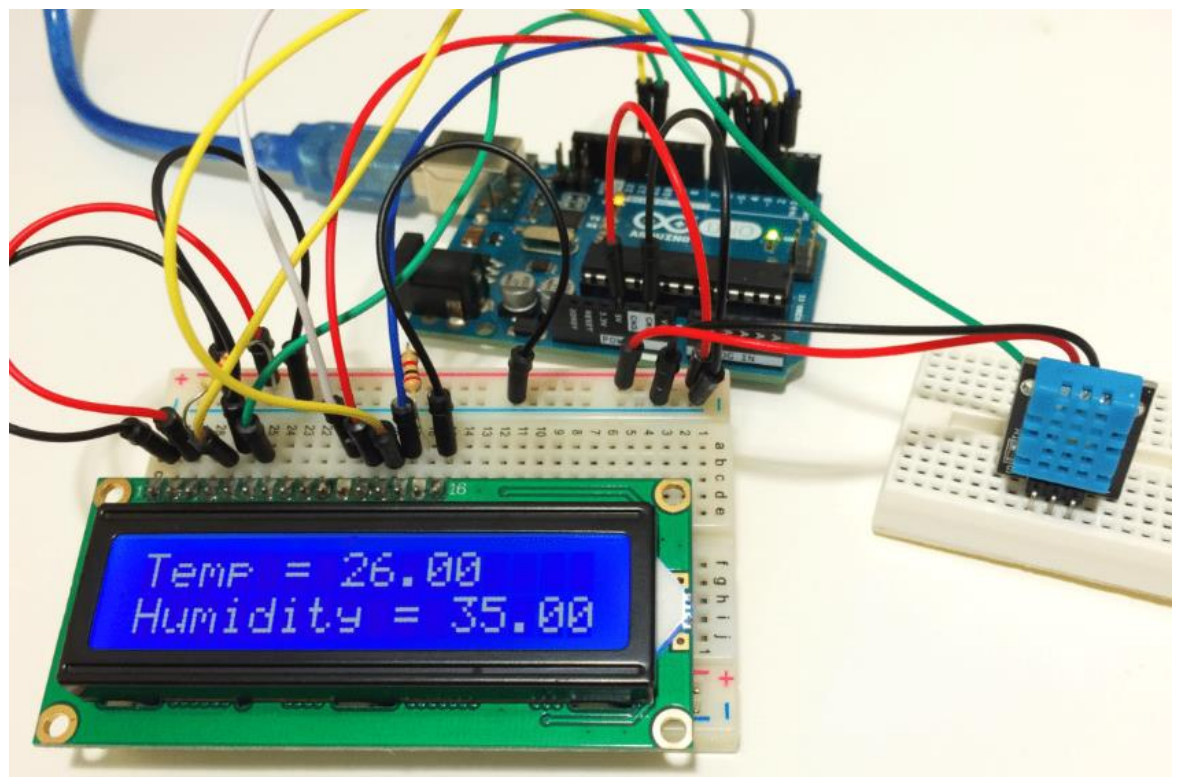

Figure 9. Results of humidity measurement

The testing is conducted in a real forestry area in dry session. The temperature and humidity, which are basic environmental parameters, used in this study are shown in Table 1 . The low-temperature of $25^{\circ} \mathrm{C}-$ $27^{\circ} \mathrm{C}$ is in the nighttime and common in tropical regions. The temperature of $35^{\circ} \mathrm{C}-37^{\circ} \mathrm{C}$ is in the daytime from $12 \mathrm{pm}$ to $3 \mathrm{pm}$.

Table 1. Forest environmental parameter

\begin{tabular}{ccc}
\hline No. & Temperature & Humidity \\
\hline 1 & $25{ }^{\circ} \mathrm{C}-27^{\circ} \mathrm{C}$ & $85 \%-90 \%$ \\
2 & $90 \%-95 \%$ \\
\hline 3 & $27{ }^{\circ} \mathrm{C}-29{ }^{\circ} \mathrm{C}$ & $85 \%-90 \%$ \\
4 & & $90 \%-95 \%$ \\
\hline 5 & $33^{\circ} \mathrm{C}-35^{\circ} \mathrm{C}$ & $70 \%-75 \%$ \\
6 & & $85 \%-90 \%$ \\
7 & & $90 \%-95 \%$ \\
\hline 8 & $35{ }^{\circ} \mathrm{C}-37^{\circ} \mathrm{C}$ & $80 \%-85 \%$ \\
9 & & $90 \%-95 \%$ \\
\hline 10 & &
\end{tabular}

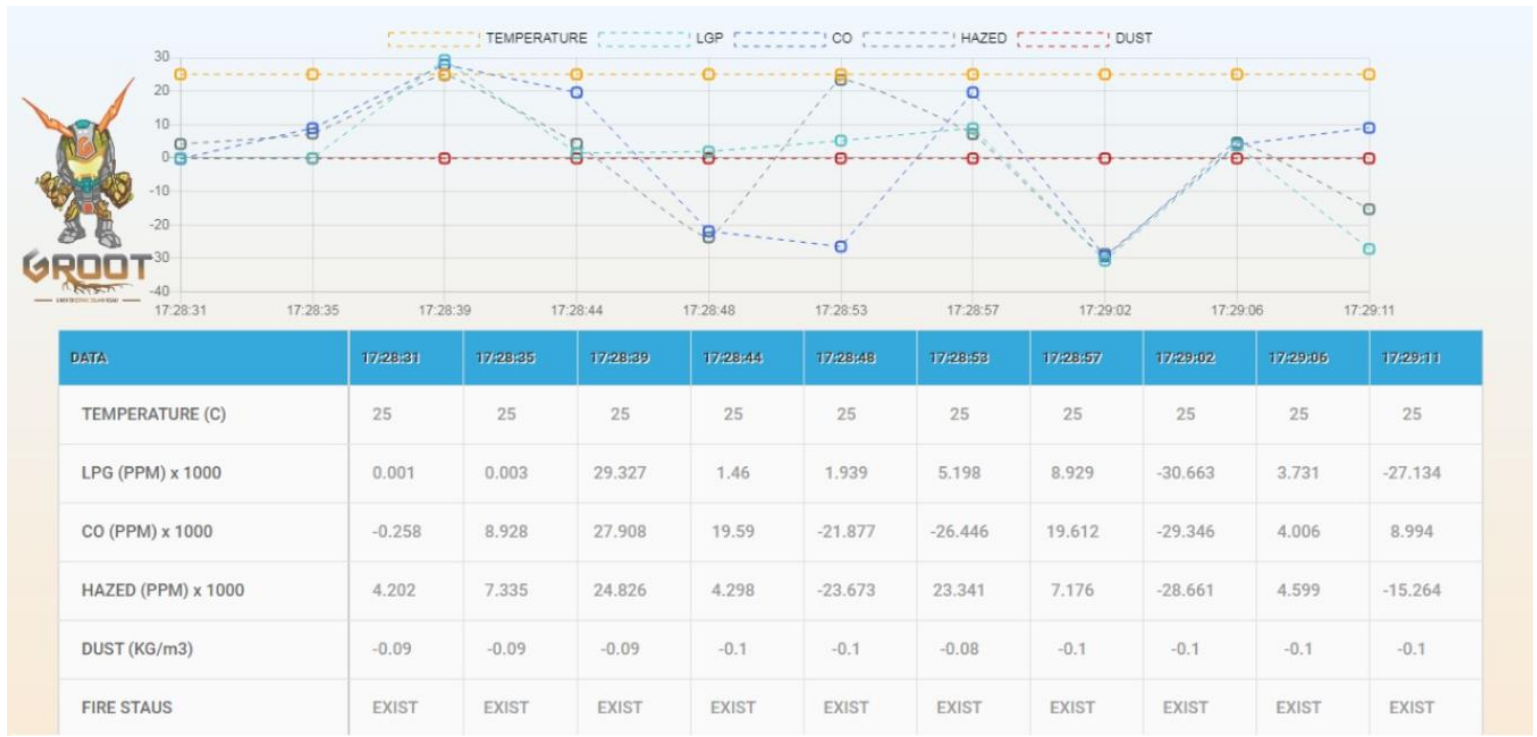

Figure 10. Testing results for a period of time in real environment 
Sensor readings for environmental parameters are tested and monitored. Figure 10 shows a graph based on the data collected for temperature, humidity, carbon, haze, and smoke. The results show that the relation between temperature and humidity in forest area is very close. Thus, the increase in temperature causes forest fire in peatland area. Carbon dioxide and haze emitted from a forest fire are very closely related to the cause of fire in peatland area. The proposed sensing system aims to detect multiple parameters to make a decision regarding forest fire occurrence. This system can provide recommendations to the authority.

\section{CONCLUSIONS}

The design of multiple sensors for forest fire detection and monitoring is proposed. The results show that the designed sensor can detect basic and additional environmental parameters of forest fire, especially in peatland area with different characteristics from other normal land or area. The graph shows a strong correlation between the increase in temperature and the increase in humidity. The readings of carbon emitted from the fire and haze concentration also justify the occurrence of fire. All the readings and detection results from the sensor system are kept in a data logger for recording. Further enhancement and improvement of the sensing system, as well as data analysis with intelligent programming and algorithm, will be conducted in the future work. The monitoring system can be coupled with a mobile reporting and alert device to provide preventive actions to the community around the forest and notifications to authorities for corresponding actions.

\section{ACKNOWLEDGMENTS}

The authors would like thank KEMENRISTEKDIKTI Indonesia for funding this research project, Universitas Islam Riau, Indonesia and Universiti Teknologi Malaysia for approval the use of facilities and mesurement.

\section{REFERENCES}

[1] X. Chen and L. Bu, "Research of Fire Detection Method Based on Multi-Sensor Data Fusion," in 2010 International Conference on Computational Intelligence and Software Engineering, 2010, pp. 1-4.

[2] J. Lin, J. Jian Xun, and W. Yan Xia, "Multi-sensor Fireproof Alarm System," in 2011 International Conference on Applied Superconductivity and Electromagnetic Devices, 2011, pp. 248-251.

[3] Y. Yao, J. Yang, C. Huang, and W. Zhu, "Fire Monitoring System Based on Multi-Sensor Information Fusion," in 2010 2nd International Symposium on Information Engineering and Electronic Commerce, 2010, pp. 1-3.

[4] R. Sowah, A. R. Ofoli, S. Krakani, and S. Fiawoo, "A web-based communication module design of a real-time multi-sensor fire detection and notification system," in 2014 IEEE Industry Application Society Annual Meeting, 2014, pp. 1-6.

[5] Y. Liang and W. Tian, "Multi-sensor Fusion Approach for Fire Alarm Using BP Neural Network," in 2016 International Conference on Intelligent Networking and Collaborative Systems (INCoS), 2016, pp. 99-102.

[6] L. Jiang, Y. Liu, Y. Li, and W. Ma, "Fire prediction based on online sequence extreme learning machine," in 2017 7th IEEE International Conference on Electronics Information and Emergency Communication (ICEIEC), 2017, pp. 568-571.

[7] E. A. Kadir;, S. L. Ros;, and A. Yulianti, "Application of WSNs for Detection Land and Forest Fire in Riau Province Indonesia," in International Conference On Electrical Engineering And Computer Science (ICECOS), Bangka Belitung, 2018: IEEE.

[8] P. Oliva and W. Schroeder, "Atmospheric correction of VIIRS and MODIS fire radiative power retrievals for multisensor comparison," in 2015 IEEE International Geoscience and Remote Sensing Symposium (IGARSS), 2015, pp. 2038-2040.

[9] A. Yoddumnern, T. Yooyativong, and R. Chaisricharoen, "The wifi multi-sensor network for fire detection mechanism using fuzzy logic with IFTTT process based on cloud," in 2017 14th International Conference on Electrical Engineering/Electronics, Computer, Telecommunications and Information Technology (ECTI-CON), 2017, pp. 785-789

[10] P. Bolourchi and S. Uysal, "Forest Fire Detection in Wireless Sensor Network Using Fuzzy Logic," in 2013 Fifth International Conference on Computational Intelligence, Communication Systems and Networks, 2013, pp. 83-87.

[11] E. A. Kadir, H. Irie, and S. L. Rosa, "Modeling of Wireless Sensor Networks for Detection Land and Forest Fire Hotspot," in The 18th International Conference on Electronics, Information, and Communication (ICEIC 2019), Auckland, New Zealand 2019.

[12] G. F. Malykhina, A. I. Guseva, and A. V. Militsyn, "Early fire prevention in the plant," in 2017 International Conference on Industrial Engineering, Applications and Manufacturing (ICIEAM), 2017, pp. 1-4.

[13] L. Xiujinag, S. Yunfeng, H. Lina, and H. Shangfeng, "The application of multi-sensor weighted measurement fusion filter in fire alarm system," in 2010 International Conference on Computer, Mechatronics, Control and Electronic Engineering, 2010, vol. 3, pp. 231-234.

[14] R. Sowah, A. R. Ofoli, S. Krakani, and S. Fiawoo, "Hardware module design of a real-time multi-sensor fire detection and notification system using fuzzy logic," in 2014 IEEE Industry Application Society Annual Meeting, 2014, pp. 1-6. 
[15] H. Xiangdong and W. Xue, "Application of fuzzy data fusion in multi-sensor fire monitoring," in 2012 International Symposium on Instrumentation \& Measurement, Sensor Network and Automation (IMSNA), 2012, vol. 1, pp. 157159.

[16] H. Hu, G. Wang, Q. Zhang, J. Wang, J. Fang, and Y. Zhang, "Design wireless multi-sensor fire detection and alarm system based on ARM," in 2009 9th International Conference on Electronic Measurement \& Instruments, 2009, pp. 3-285-3-288.

[17] A. Trucco, F. Traverso, and M. Crocco, "Maximum Constrained Directivity of Oversteered End-Fire Sensor Arrays," Sensors, vol. 15, no. 6, pp. 13477-13502, 2015.

[18] J.-G. Kang, D.-W. Lim, and J.-W. Jung, "Energy-Efficient Forest Fire Prediction Model Based on Two-Stage Adaptive Duty-Cycled Hybrid X-MAC Protocol," Sensors, vol. 18, no. 9, pp. 2960-2971, 2018.

[19] N. Kalatzis et al., "Semantic Interoperability for IoT Platforms in Support of Decision Making: An Experiment on Early Wildfire Detection," Sensors, vol. 19, no. 3, pp. 528-567, 2019.

[20] E. A. Kadir;, A. Efendi, and S. L. Rosa, "Application of LoRa WAN Sensor and IoT for Environmental Monitoring in Riau Province Indonesia," in 5th International Conference on Electrical Engineering, Computer Science and Informatics (EECSI 2018), Malang, 2018.

\section{BIOGRAPHY OF AUTHORS}

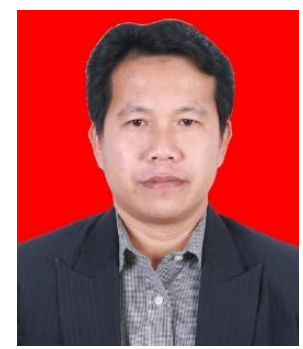

Evizal Abdul Kadir received his Master of Engineering and $\mathrm{PhD}$ in Wireless Communication at the Faculty of Electrical Engineering, Universiti Teknologi Malaysia in 2008 and 2014, respectively. He is currently a Lecturer and Researcher in Islamic University of Riau, Indonesia and a Director of research institute and community services and promoted to Associate Professor. He has worked in several companies that provide a system solution in wireless communication and radio frequency and radio frequency identification. He is currently continuing his research activities related to wireless communication system, antenna, remote sensing, radio frequency identification, wireless sensor network, wireless and mobile monitoring system, and IoT.

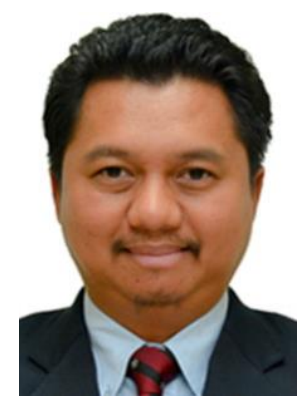

Sharul Kamal Abdul Rahim received the degree in electrical engineering from the University of Tennessee, USA, the M.Sc. Degree in Engineering (communication engineering) from Universiti Teknologi Malaysia, and the Ph.D. Degree in wireless communication systems from the University of Birmingham, U.K., in 2007. After his graduation from the University of Tennessee, he spent 3 years in the industry. He joined UTM in 2001. He is currently a Professor in the Wireless Communication Center. He has published over 200 learned papers in various journals, including the IEEE Antenna and Propagation Magazine, the IEEE Transactions on Antenna and Propagation, the IEEE Antenna and Propagation Letters, and taken various patents. His research interests include antenna design, smart antenna systems, beamforming networks, and microwave devices for fifth-generation mobile communication. He is a Senior Member of the IEEE Malaysia Section, a member of the Institute of Engineer Malaysia, a Professional Engineer with BEM, a member of the Eta Kappa $\mathrm{Nu}$ Chapter, the University of Tennessee, and the International Electrical Engineering Honor Society. He is currently an Executive Committee of the IEM Southern Branch.

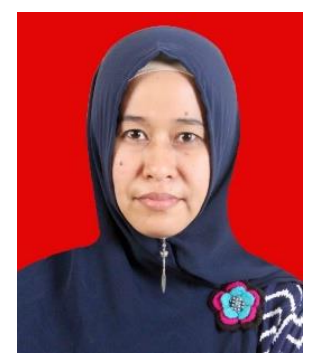

Sri Listia Rosa obtained the Bachelor Degree in Electrical Engineering from Universitas Bung Hatta Padang and obtained Master Degree in Computer Science and Information System from Universiti Teknologi Malaysia in 2013. She has been a Lecturer in the Department of Informatics Engineering, University Islam Riau since 2015. Her current research interests include computational intelligent and machine learning. 